\title{
ASPECTOS MOTIVACIONAIS E ESTRATÉGICOS NA INTERNACIONALIZAÇÃO DE EMPRESAS BRASILEIRAS
}

\section{RESUMO}

0 artigo discute os resultados de uma pesquisa sobre o comportamento internacional de firmas sob o foco de duas perspectivas teóricas importantes: a motivacional e a estratégica. 0 trabalho tem por objetivo identificar os fatores motivacionais e estratégicos presentes nas decisões internacionais e ainda pretende examinar as diferenças potenciais entre esses fatores tendo por base o tamanho da firma, a experiência internacional, estratégias anteriores de entrada e o envolvimento com vendas internacionais. Foi realizado um survey com 73 exportadoras brasileiras do setor de manufatura classificadas no Ministério do Desenvolvimento, Indústria e Comércio Exterior. Os resultados evidenciam que fatores de ordem gerencial e associados aos mercados interno e externo impulsionam os negócios internacionais das empresas pesquisadas, elementos racionais e centralizadores demarcam o processo estratégico internacional, e diferenças significativas são observadas entre a maioria desses fatores em relação a tamanho, modo de entrada e envolvimento com vendas internacionais.

\section{Luiz Honório}

Faculdade Novos Horizontes

\section{Suzana Braga Rodrigues}

FACE-FUMEC e Birmingham University

\begin{abstract}
This article discusses firm's international behavior under two major theoretical streams: the motivational and the strategic perspectives. The research aims at identifying the motivational and strategic factors involved in international decisions. It is also intended to examine the potential differences between these factors based on firm size, international experience, strategies of market entry and involvement in international sales. A survey was carried with 73 Brazilian exporters classified according to the Ministry of D evelopment, Industry and Foreign Trade. The results showed that managerial factors and those associated with internal and external markets were the driving factors of international businesses of the companies that were researched; rational and centralizing elements determined the international strategic process; and significant differences were found between the majority of these factors in relation to size, methods of market entry and involvement in international sales.
\end{abstract}

PALAVRAS-CHAVE Internacionalização, negócios internacionais, processo de formação estratégica, motivação internacional, características organizacionais.

KEYWORDS Internationalization, international trade, process of strategy formation, international motivation, organizational factors. 


\section{INTRODUÇÃO}

U ma parte da literatura especial izada em gestão internacional conceitua a internacionalização como um movimento das operações de uma firma para o exterior, envolvendo uma série de decisões baseadas em critérios objetivos e na avaliação de estratégias de entrada no mercado estrangeiro (Andersen, 1997). Entre esses fatores, destacam-se 0 modo como as estratégias internacionais são formuladas e os tipos de estratégias que podem ser escolhidas para a realização de operações no mercado internacional (Root, 1994; Smith eZeithaml, 1999; Lu e Beamish, 2001; Spence, 2003; Crick e Spence, 2004). Além disso, vários estudos têm evidenciado que diferentes motivos estimulam uma firma a se internacionalizar, e que o papel do empreendedor é decisivo nas operações internacionais (Leonidou, 1995; Katsikeas, 1996; Dimitratos e Plakoyiannaki, 2003). Neste artigo, tais fatores são analisados em termos das perspectivas estratégica e motivacional presentes em estudos sobre o comportamento internacional da firma.

É preciso reconhecer que os fatores de ordem motivacional e estratégica estão interligados, no que se refere às atividades de internacionalização. Pressupõe-se que, inicialmente, determinados estímulos internos e externos à firma a impulsionam em direção ao mercado internacional (Katsikeas e Piercy, 1993; Leonidou, 1995). Contatos realizados em feiras comerciais ou o recebimento de eventuais pedidos de compradores estrangeiros, por exemplo, poderiam despertar 0 interesse pelo mercado internacional. Em seguida, por meio de um processo de decisões, planejadas ou não, a firma formula e escolhe as estratégias para entrar e desenvolver operações no mercado estrangeiro (Melin, 1992; Smith e Zeithaml, 1999; Spence, 2003; Crick e Spence, 2004). Em ambos os momentos, o papel do empreendedor é de suma importância, uma vez que ele é reconhecido como uma das forças-chave necessárias para identificar, explorar e tomar decisões a respeito das oportunidades que surgem no mercado internacional (Katsikeas, 1996; Dimitratos e Plakoyiannaki, 2003; Crick e Spence, 2004).

Os pesquisadores também têm evidenciado o papel que determinadas características da firma ocupam no comportamento orientado para o mercado estrangeiro. Entre essas características, sobressaem-se: tamanho (Gripsrud, 1990; Holzmüller e Kasper, 1991; Katsikeas e Piercy, 1993; Zahra et al., 2000); experiência internacional (Johanson e Wiedersheim-Paul, 1975; Johanson e Vahlne, 1977; Gripsrud, 1990; Katsikeas e Piercy, 1993); e envolvimento com vendas internacionais (Diamantopoulos e Inglis, 1988; Katsikeas e Piercy, 1993).
Este artigo sustenta que deveria ser levada adiante uma investigação mais robusta e completa a respeito das operações da firma no mercado internacional, em que se aval iasse a possibilidade de se contemplar em uma única pesquisa diferentes perspectivas sobre o tema. N este caso, o propósito central é considerar as perspectivas motivacional e estratégica.

Tendo em vista as razões expostas, este artigo pretende identificar: a) a estrutura dos fatores motivacionais e estratégicos presentes nas atividades internacionais de empresas brasileiras do setor de manufatura; e b) as diferenças potenciais entre os fatores motivacionais e estratégicos identificados com base no tamanho da firma, na experiência internacional, nas estratégias de entrada e no envolvimento com vendas internacionais. Para alcançar tais objetivos, o artigo está estruturado em quatro seções. Na primeira, são revisadas três dimensões teóricas, a saber: motivação internacional, processo de formação de estratégias internacionais, e características da firma determinantes da real ização de operações no mercado estrangeiro. $\mathrm{N}$ a segunda, discutem-se os procedimentos metodológicos utilizados na pesquisa. $\mathrm{N}$ a terceira, os resultados são apresentados e discutidos. Por fim, na quarta, apresentam-se as conclusões do trabalho.

\section{REVISÃO DE LITERATURA}

\section{Motivação internacional}

Pelo menos dois campos de pesquisa podem ser debatidos quando o tema a ser tratado envolve a motivação internacional: estímulos à exportação e empreendedorismo internacional. Estímulos à exportação são conceituados como os fatores que influenciam a decisão da firma para iniciar, desenvolver emanter operações de exportação. De forma mais ampla, eles fornecem a força motriz necessária para impulsionar a firma em direção ao caminho da internacional ização. Os fatores de motivação à exportação são afetados por determinadas forças antecedentes, derivadas de três fontes principais: a) características individuais; b) características organizacionais; ec) características ambientais. As características individuais dizem respeito às percepções do tomador de decisões sobre as oportunidades que surgem do mercado internacional. Entre elas, podem ser citadas características pessoais, orientação internacional, estilo de liderança, competência gerencial e expectativas gerenciais. Q uanto às características organizacionais, destacam-se os objetivos corporativos, as disponibilidade de recursos, a natureza dos produtos e as vantagens 
diferenciais da firma. Finalmente, localização do país, disponibilidade de insumos para a produção, condições econômicas dominantes, facilidades de infra-estrutura e políticas governamentais de apoio à internacionalização configuram-se como características ambientais (Katsikeas e Piercy, 1993; Leonidou, 1995).

Leonidou (1995) argumenta que os estímulos que motivam a exportação podem ser classificados como internos e externos. Os estímulos internos estão associados às características individuais e organizacionais da firma, ao passo que os estímulos externos se associam às características do ambiente em que a firma realiza suas atividades, seja ele doméstico ou internacional. No levantamento realizado por Leonidou (1995), os principais estímulos internos que prevaleceram relacionam-se às características organizacionais. Por ordem de importância, foram apontados os seguintes estímulos: disponibilidade de capacidade de produção não utilizada, potencial de lucro extra, produção de bens com qualidades singulares, potencial de crescimento extra, necessidade de reduzir dependência, e risco em relação ao mercado doméstico. Q uanto aos estímulos externos, os que preponderaram, em seqüência de importância, foram os seguintes: recebimento de ordens eventuais do mercado internacional, saturação/retração do mercado doméstico, intensificação da competição no mercado doméstico, oportunidade de lucro e crescimento no mercado internacional, e incentivos de agentes ou organizações externos.

Os estudos sobre empreendedorismo internacional, diferentemente daqueles que abordam estímulos à exportação, associam-se a todo e qualquer modo de entrada no mercado estrangeiro, como também se centram especificamente no papel que o empreendedor ocupa nas operações internacionais. A literatura define o empreendedorismo internacional como um processo organizacional amplo, inserido na cultura da firma, que busca, por meio da exploração de oportunidades surgidas no mercado internacional, gerar valor para a firma (Dimitratos e Plakoyiannaki, 2003; Zahra et al., 2004). Na opinião de Dimitratos e Plakoyiannaki (2003), o capital humano empreendedor é uma das forças-chave que a firma possui para obter vantagem com as oportunidades que surgem no mercado internacional. Portanto, as percepções, crenças e práticas gerenciais empreendedoras podem estimular a entrada e o desenvolvimento de uma firma no mercado estrangeiro. Há outros fatores motivacionais individuais que podem levar à exploração de oportunidades internacionais. Dentre eles, temos o nível mais alto de escolaridade do empreendedor, procedência estrangeira, e experiência internacional pregressa.
Acredita-se que a motivação para se internacionalizar está em estreita relação com o processo de formação e escolha das estratégias que a firma estabel ece para reconhecer e explorar as oportunidades oferecidas pelo mercado internacional (Shane e Venkataraman, 2000; Dimitratos e Plakoyiannaki, 2003; Zahra et al., 2004). Esse tema será tratado a seguir.

\section{Processo de formação e escolha das estratégias internacionais}

$\mathrm{N}$ a opinião de Melin (1992), o processo de formação estratégica envolve perspectivas de mudança ou de posicionamento da firma no mercado. Para esse autor, a internacional ização, considerada como uma atividade que amplia o envolvimento da firma com operações além das fronteiras nacionais, compreen de tais perspectivas e se constitui na principal dimensão de expansão de muitas firmas de negócios. Essa linha de raciocínio também está presente nas considerações de Smith e Zeithaml (1999). A internacionalização, na perspectiva desses autores, é tratada como uma atividade que leva a firma a expandir suas operações além de seus limites domésticos para se posicionar em novos mercados internacionais. Por essa razão, os autores mencionados argumentam que o envolvimento da firma com o mercado internacional deveria estar explicitamente conectado à literatura sobre pensamento estratégico e constituir-se em um debate constante sobre como as estratégias internacionais são formuladas em diferentes contextos organizacionais e industriais. Antes que tal conexão seja feita, é importante discutir, ainda que brevemente, as dimensões teóricas do processo de formação estratégica sugeridas para esse fim.

A estratégia é definida como um padrão que se estabelece em um fluxo de decisões, de modo que o relacionamento entre planos de liderança, intenções e o que real mente foi implementado nas organizações possa ser explorado. Duas modalidades de estratégias podem ser distinguidas: deliberadas e emergentes. Estratégias deliberadas são aquelas planejadas, prognosticadas e controladas pela alta gerência, enquanto as estratégias emergentes são consideradas padrões ou consi stências que surgem de ações destituídas de uma inten ção definida ou consciente da alta gerência (M intzberg eW aters, 1985; M intzberg, 1998). Hart (1992) propõetipos de estratégias que variam segundo um continuum processual de formação estratégica, tanto deliberada quanto emergente, e que se distinguem em termos de determinadas características associadas: a) à orientação visível da alta gerência no processo estratégico; (b) à interação contínua entre dar e receber insumos necessários 
ao desenvolvimento e à implementação da estratégia; e (c) à participação de camadas hierárquicas inferiores da organização no direcionamento estratégico. Segundo Hart (1992), as estratégias deliberadas são fortemente direcionadas e controladas pela alta gerência e incorporam modos de formação estratégica dos tipos comando, simbólico e racional. As estratégias emergentes, ao contrário, são estabelecidas tanto por meio do diálogo contínuo entre a al ta gerência e atores organizacionais internos e externos como pelo incentivo ao empreendedorismo interno na organização. Essas características configuram modos de formação estratégica dos tipos transativo e generativo, respectivamente.

Conectando a literatura sobre pensamento estratégico aqui resumidamente discutido com o tema da internacionalização, observa-se que muitos estudos têm sugerido que os processos estratégicos, tanto deliberados quanto emergentes, fazem parte da entrada e do desenvolvimento da firma em mercados internacionais (M erilees et al., 1998; Smith e Zeithaml, 1999; Spence, 2003; Crick e Spence, 2004).

Crick e Spence (2004) argumentam que as decisões internacionais não são tão racionais e planejadas como a literatura sugere. De um lado, a aprendizagem ocupa um espaço no processo, e as equipes gerenciais reagem às experiências aprendidas ao longo do tempo. De outro lado, um comportamento empresarial não planejado se expressa como reação às oportunidades que se expõem à organização ou aos problemas que podem surgir na forma de incidentes críticos à medida que a firma se desenvolve internacionalmente. Essas considerações sugerem que 0 processo estratégico de internacionalização deve apresentar um componente de adaptabilidade, ressaltando a presença decisiva de estratégias emergentes nas atividades internacionais da firma.

As conclusões dos estudos que investigavam o processo estratégico internacional de pequenas e médias empresas evidenciaram que o planejamento formal não foi deliberado com vistas à produção de um plano de marketing internacional. As estratégias tornavam-se planejadas à medida que os gerentes iam adquirindo experiência com as operações internacionais ou obtendo recursos financeiros necessários a uma expansão internacional, em termos de estrutura organizacional, provisionamento de pessoal e modos de entrada de maior comprometimento com o mercado internacional (Spence, 2003; Crick e Spence, 2004). No que tange às grandes empresas, um estudo realizado por Smith eZeithaml (1999) mostrou que as decisões internacionais de firmas desse porte também combinavam estratégias deliberadas e emergentes. Mas apesar da pre- sença marcante da al ta gerência na condução do processo internacional, o sucesso das atividades internacionais de uma firma não parecia determinado exclusivamente por um planejamento estratégico sistemático ou por um controle estabelecido pela alta gerência.

0 processo de formação estratégica internacional se concretiza com a escol ha de diversas modal idades de entrada no mercado estrangeiro, as quais variam em função do nível de comprometimento de recursos e da complexidade inerentes às operações internacionais. Estratégias de entrada mais simples (via exportação) envolvem níveis mais baixos de comprometimento de recursos e de complexidade. Estratégias de entrada mais avançadas (via investimento direto - aquisição, joint venture ou projetos greenfield) implicam maior comprometimento de recursos e complexidade associados às operações internacionais ( $\mathrm{Hill}$ et al., 1990; Root, 1994; Buckley e Casson, 1998). Estratégias avançadas são viáveis quando uma firma preten de potencializar o acesso a recursos (físicos ou humanos) necessários a um aumento de competitividade internacional (Lu e Beamish, 2001). Relatório divulgado pela Conferência das $\mathrm{N}$ ações Unidas para 0 Comércio e o Desenvolvimento (Unctad) em dezembro de 2004 apontou que poucas empresas brasileiras comprometiam maiores recursos no estrangeiro. Segundo o relatório, al gu mas empresas brasileiras haviam investido no exterior procurando acessar recursos naturais; outras, buscando evitar barreiras comerciais ou aperfeiçoar infraestrutura de logística necessária às exportações; e outras, procurando seguir ou estar próximas de grandes clientes para melhor atender às suas necessidades.

\section{Características da firma e o comportamento orientado para negócios internacionais}

O comportamento motivacional e estratégico orientado para a realização de negócios internacionais deve ser examinado em associação com determinadas características da firma que parecem ser vitais para o desenvolvimento de operações no mercado estrangeiro. Tamanho da firma, experiência internacional e volume de vendas internacionais estão entre as características mais abordadas pela literatura sobre internacionalização.

\section{Tamanho da firma}

N a opinião de Katsikeas e Piercy (1993), não existe concordância a respeito do impacto que o tamanho pode causar nas operações realizadas no mercado estrangeiro. A pesar disso, seria razoável sugerir que firmas maiores, comparadas às menores, devem ser mais capazes de perceber uma variedade mais ampla de sinais associados ao 
mercado internacional e de responder de modo mais positivo a eles. Geralmente, é aceito pela literatura que as firmas maiores possuem mais recursos e mais possibilidades de entrar em mercados mais distantes, que podem exigir esforços adicionais (Gripsrud, 1990). Todavia, outros estudos mostraram uma realidade diferente. Por exemplo, Holzmüller e Kasper (1991) e Zahra et al. (2000) evidenciaram que o tamanho da firma provou ter pouca ou nenhuma influência sobre o desempenho corporativo em termos de retornos financei ros advindos das operações internacionais.

\section{Experiência internacional}

Uma das mais difundidas teorias sobre internacionalização afirma que a falta de conhecimento sobre mercados e operações estrangeiros é um grande obstáculo ao desenvolvimento de transações internacionais, e que a sua aquisição pode ocorrer experimentalmente por meio de atividades no exterior. Significa dizer que 0 conhecimento experiencial sobre o mercado e as operações que nele se desenvolvem geram oportunidades de negócios e impulsionam decisões orientadas para um maior comprometimento de recursos com o mercado exterior (J ohanson e Wiedersheim-Paul, 1975; Johanson e Vahlne, 1977). Evidências empíricas atestam que 0 conhecimento adquirido do mercado e os contatos ali realizados condicionarão um aumento das futuras exportações (Gripsrud, 1990).

\section{Envolvimento com vendas internacionais}

0 percentual de vendas realizadas no mercado internacional tem sido o indicador mais utilizado para distinguir firmas de maior e de menor envolvimento com operações internacionais (Diamantopoulos e Inglis, 1988; Katsikeas e Piercy, 1993). Tal indicador é usualmente utilizado em estudos que investigam o comportamento exportador da firma. Um desses estudos evidenciou que as firmas mais envolvidas com o mercado internacional, apresentando percentuais de vendas internacionais acima de 50\%, mostravam capacidades internas mais desenvolvidas para identificar e explorar oportunidades de exportação (Diamantopoulos e Inglis, 1988). Já o estudo de Katsi keas e Piercy (1993) mostrou que as firmas de menor envolvimento internacional eram motivadas por pressões do mercado doméstico, ao passo que aquelas de maior envolvimento eram mais direcionadas por condições específicas do comércio internacional que estão além do domínio da firma ou por dimensões associadas a uma política nacional de exportação.

\section{METODOLOGIA}

Esta pesquisa pode ser caracterizada como um levantamento de campo do tipo survey, realizado ex post facto, com caráter exploratório, descritivo e explicativo. 0 caráter exploratório se fundamenta pela tentativa de integrar os aspectos motivacionais e estratégicos que caracterizam o comportamento internacional da firma. As pesquisas nesse campo usualmente tratam desses aspectos isoladamente. 0 caráter descritivo justifica-se pela aplicação de um instrumento quantitativo que tem por finalidade investigar: a) o comportamento da firma relacionado aos principais indicadores que caracterizam os processos de motivação e formação estratégica internacional; e b) as diferenças potenciais entre o comportamento internacional motivacional e o estratégico com base no tamanho da firma, na experiência internacional, nas estratégias de entrada e no volume de vendas internacionais. 0 caráter explicativo apóia-se na utilização de procedimento estatístico multivariado (análise fatorial), que visa revelar os fatores subjacentes aos indicadores motivacionais e estratégicos identificados na análise descritiva.

Participaram da pesquisa empresas exportadoras brasileiras do setor de manufatura classificadas em uma base de dados do Ministério do Desenvolvimento, Indústria e Comércio Exterior. Foram selecionadas dessa base de dados as 700 maiores exportadoras brasileiras no ano de 2004. Esse total foi escolhido intencionalmente porque incluía um rol de pequenas, médias e grandes empresas que representavam a importância da atividade exportadora para o país, bem como se tratava de um número que poderia também refletir outras modalidades de realização de negócios internacionais além da exportação. A intenção de utilizar o setor de manufatura deveu-se ao fato de as pesquisas no campo da internacionalização fundamentalmente 0 utilizarem como base de levantamento de dados. A amostra final foi composta por 73 empresas, o que perfaz um percentual de retorno de $10,5 \%$ dos questionários enviados via correio. A unidade de observação foi composta por presidentes, diretores comerciais, diretores de marketing e outros profissionais mais estrategicamente envolvidos com operações internacionais. Os dados da pesquisa foram colhidos em junho de 2005.

Utilizou-se um questionário estruturado, que se compunha de três partes: características gerais da empresa ea sua inserção no mercado internacional; formação e escolha de estratégias internacionais; e motivação internacional. A primei ra parte englobava questões dispostas em escalas 
ordinais, que posteriormenteforam dicotomizadas para os fins de anál ise dos dados, enquanto a segunda e a terceira parte foram dispostas em escal as interval ares de concordância e importância de cinco pontos do tipo Likert. Em seguida, para fins de validação de forma e conteúdo, 0 instrumento foi pré-testado e refinado por meio de entrevistas com acadêmicos familiarizados com o tema e com executivos envolvidos com negócios internacionais.

A estatística descritiva foi utilizada para identificar os principais indicadores motivacionais e estratégicos que orientam as operações internacionais da firma. Como medidas descritivas para esta parte do questionário foram adotadas a média e a mediana. A mbas foram empregadas respeitando-se as considerações de Malhotra (2001) de que podem ser usadas em escalas intervalares. U tilizaramse também medidas de dispersão do tipo intervalo interquartil ( P25 e P75), uma vez que tais percentis representam bem o posicionamento da unidade amostral. 0 teste t de Student foi aplicado para investigar se poderiam ser observadas diferenças potenciais quanto aos fatores motivacionais e estratégicos com base no tamanho da firma, na experiência internacional, nas estratégias de entrada e no volume de vendas internacionais. Os fatores motivacionais e estratégicos envolvidos no teste t foram extraídos mediante a realização de uma análise fatorial exploratória (Afex), enquanto as características organizacionais foram dicotomizadas em amostras independentes, conforme os critérios explicitados no parágrafo seguinte.

A literatura comumente classifica como pequena empresa aquela que tem até 100 empregados, como média a que tem até 500, e como grande empresa a que tem acima de 500 empregados. Essa classificação geral foi adotada pela pesquisa, tendo sido dicotomizada em empresas menores, aquelas com 500 empregados ou menos, e em empresas maiores, aquel as que apresentavam acima de 501 empregados. Firmas com 11 anos ou mais de atuação no mercado internacional foram consideradas mais experientes, enquanto firmas com 10 anos ou menos foram classificadas como menos experientes (Katsikeas e Piercy, 1993). As estratégias de entrada foram dicotomizadas em estratégias mais simples de entrada (exportação e contratos de produção) e estratégias mais avançadas de entrada (aquisição, parcerias e investimentos do tipo greenfield) (Root, 1994). Foram classificadas como empresas mais envolvidas aquelas que apresentavam um percentual de vendas realizadas no mercado internacional de $56,0 \%$ ou mais em relação ao total de vendas; e como firmas menos envolvidas, aquelas com percentual de $55,0 \%$ ou menos (Diamantopoulos e Inglis, 1988; Katsikeas e Piercy, 1993).

\section{APRESENTAÇÃO E DISCUSSÃO DOS RESULTADOS}

\section{Resultados descritivos: características gerais das empresas pesquisadas}

Participaram desta pesquisa 73 firmas, as quais foram classificadas por tamanho, experiência internacional, estratégias de entrada e percentual de vendas internacionais. Em termos de tamanho, o conjunto de empresas menores atingiu um percentual de $59,0 \%$, contra $41,0 \%$ das empresas maiores. Quanto à experiência internacional, 75,0\% da amostra ficou composta por empresas mais experientes, contra $25,0 \%$ de empresas menos experientes. Em relação às estratégias de entrada, $77,0 \%$ utilizam estratégias mais simples (exportação e contratos de produção), contra apenas $23,0 \%$ daquelas que utilizam estratégias mais avançadas de entrada. Predominam as parcerias internacionais (por exemplo, alianças estratégicas ou joint ventures), seguidas por aquisição de empresas ou plantas no exterior e, em menor número, por modalidade do tipo greenfield. No que se refere ao envolvimento com vendas internacionais, $48,0 \%$ foram classificadas como empresas mais envolvidas, contra $52,0 \%$ classificadas como empresas menos envolvidas.

Em síntese, os dados acima denotam que as empresas brasileiras pesquisadas, apesar de demonstrarem experiência internacional e envolvimento com o mercado estrangeiro em função do volume de vendas, utilizam estratégias de entrada consideradas de menor complexidade e comprometimento de recursos. Essas evidências confirmam os pressupostos teóricos de que um maior conhecimento de mercado condiciona acréscimo nas exportações (Gripsrud, 1990) e reforça o relatório da Unctad (2004), que aponta a exportação como a estratégia de entrada preferida das empresas brasileiras, indicando que a predominância acentuada desse tipo de modalidade sugere um baixo grau de internacional ização.

\section{Resultados descritivos: aspectos motivacionais e estratégicos}

Tendo em vista que os aspectos motivacionais e estratégicos foram estabelecidos no instrumento de coleta de dados por meio de escalas de respostas do tipo Likert de cinco pontos, considerou-se como escore médio, ou mediana, o valor 3,0. A escala motivacional requisitava a descrição do grau de importância atribuída aos motivos que justificavam a realização de negócios internacionais, segundo a tipologia de Katsikeas e Piercy (1993) sobre as características individuais, organizacionais e ambientais representativas de estímulos à exportação, ao passo que a escala sobre os aspectos estratégicos solicitava que 
o respondente descrevesse seu grau de concordância com sentenças que caracterizavam os modos de formação estratégica da tipologia de Hart (1992): comando, si mbólico, racional, transativo egenerativo. Como os graus de importância ou concordância nessas escalas graduavam-se de "nem um pouco importante" a "muito importante" e de "discordo totalmente" a concordo totalmente, segue-se que as variáveis que apresentavam escores acima de 3,0 indicavam uma situação de importância ou concordância. Escores abaixo desse valor indicavam uma situação de pouca ou nenhuma importância, como também de discordância parcial ou total.

No que diz respeito ao processo de motivação internacional, os informantes deram mais importância aos seguintes motivos: oportunidade de lucro e crescimento no mercado internacional $(4,4)$; necessidade de reduzir a dependência do mercado doméstico $(3,7)$; necessidade de reduzir os riscos em relação ao mercado doméstico $(3,5)$; interesse gerencial em relação a atividades internacionais $(3,5)$; e crenças gerenciais sobre a importância da internacionalização $(3,4)$. Essas respostas enfatizam que as empresas brasileiras pesquisadas são mais significativamente motivadas por fatores externos ligados tanto ao mercado exterior quanto ao doméstico, eque a orientação da gerência exerce papel importante nas decisões internacionais. Tais resultados não confirmam as conclusões do levantamento de Leonidou (1995), cujos motivos principais estiveram associados à capacidade de produção não utilizada da firma e ao recebimento de pedidos eventuais do mercado internacional. Os respondentes não deram im- portância a motivos associados a programas governamentais apoiando a internacionalização, a incentivos recebidos de agentes externos, a contatos casuais impul sionando negócios internacionais e à existência de gerente de origem estrangeira na empresa, todos el es apresentando médias iguais ou inferiores a 2,4. Isso demonstra dois pontos: primeiro que as empresas pesquisadas não se beneficiam de subsídios públicos ou institucionais para as suas operações internacionais; e segundo, que talvez precisem se tornar mais empreendedoras para obter vantagem das oportunidades que surgem no mercado internacional (Dimitratos e Plakoyiannaki, 2003; Spence, 2003; Crick e Spence, 2004). Esses resultados estão na Tabela 1.

Quanto ao processo deformação de estratégias internacionais, os respondentes concordaram significativamente que: a idéia da estratégia partia da al ta administração $(4,2)$; a alta administração respondia pelas decisões relativas ao curso da estratégia $(4,0)$; os valores, as crenças e os costumes definiam o estabel ecimento da estratégia $(3,9)$; a alta administração controlava total mente o processo estratégico $(3,9)$; a alta administração tinha o papel de comunicar e explicitar a estratégia $(3,8)$; a escol ha estratégica respeitava um processo seqüencial analítico e procedimental $(3,7)$; e verificações de ajuste da estratégia eram realizadas após a sua implementação $(3,7)$. A Tabela 2 identifica esses resultados e indica como eles se posicionam em termos amostrais.

É importante observar na Tabel a 2 que 75,0\% da amostra evidenciou escores iguais ou superiores a 4,0 quando a mediana era considerada, denotando que esses resulta-

Tabela 1 - Caracterização da amostra segundo as variáveis de motivação internacional

\begin{tabular}{|l|c|c|c|c|}
\hline \multicolumn{1}{|c|}{ VARIÁVEIS } & \multicolumn{3}{|c|}{ MEDIDAS DESCRITVAS } \\
\cline { 2 - 5 } & MÉDIA & $P_{25}$ & MEDIANA & $P_{75}$ \\
\hline Oportunidade de lucro e crescimento no mercado internacional. & 4,44 & 4,0 & 5,0 & 5,0 \\
\hline Necessidade de reduzir a dependência do mercado doméstico. & 3,71 & 3,0 & 4,0 & 5,0 \\
\hline Necessidade de reduzir os riscos em relação ao mercado doméstico. & 3,56 & 3,0 & 4,0 & 5,0 \\
\hline Interesse gerencial em relação a atividades internacionais. & 3,56 & 3,0 & 4,0 & 5,0 \\
\hline Crenças gerenciais sobre a importância da internacionalização. & 3,47 & 2,5 & 4,0 & 5,0 \\
\hline Capacidade de produção disponível não utilizada. & 3,33 & 2,0 & 4,0 & 5,0 \\
\hline Habilidade para modificar produtos para o mercado internacional. & 3,33 & 2,0 & 4,0 & 5,0 \\
\hline Incentivos de agentes ou organizações externos. & 2,40 & 1,0 & 2,0 & 3,0 \\
\hline Contatos casuais em feiras ou missões comerciais. & 2,37 & 1,0 & 2,0 & 3,0 \\
\hline Programas governamentais de promoção à internacionalização. & 2,10 & 1,0 & 2,0 \\
\hline Existência de gerente de origem estrangeira na empresa. & 1,56 & 1,0 & 2,0 \\
\hline
\end{tabular}


dos mostram a presença marcante da al ta administração no processo estratégico internacional e que as estratégias internacionais das empresas brasileiras são mais deliberadas por meio do comando (top-down) e da racional idade (processo procedimental analítico e de ajustamento).

\section{Análise fatorial, confiabilidade e adequação da amostra}

A anál ise fatorial foi realizada de forma exploratória, pois se pretendia investigar a existência de fatores subjacentes relativos aos indicadores motivacionais e estratégicos identificados na análise descritiva. Os fatores extraídos foram também utilizados, subseqüentemente, para testar diferenças potenciais baseadas no tamanho da firma, na experiência internacional, nas estratégias de entrada e no envolvimento com vendas internacionais. 0 modelo final resultou na extração de cinco fatores compostos por variáveis que perfaziam cargas fatoriais iguais ou superiores a 0,6 em sua grande maioria, val or adequado para pesquisas de natureza exploratória (Hair et al., 1998). 0 método de extração se deu pela análise de componentes principais e o de rotação pelo método Varimax com normalização Kaiser. Os fatores retidos para análise respondiam por $40,5 \%$ e $38,5 \%$ da variância para a soma média das cargas individuais referentes às dimensões motivacional e estratégica, respectivamente. Percentuais de explicação abaixo de $60,0 \%$ são considerados aceitáveis, uma vez que as informações no campo das ciências sociais são freqüentemente menos precisas (Hair et al., 1998). A medida KM O
(Kaiser-M eyer-Olkin) para ambas as dimensões de fatores extraídos foi superior a 0,6 , indicando que a amostra era adequada para a matriz de correlação inteira e para cada variável individual avaliada. 0 alfa de Cronbach foi superior a 0,6 para os fatores motivacionais e a 0,7 para os fatores estratégicos, revelando que a confiabilidade do modelo foi satisfatoriamenteal cançada (Hair et al., 1998). As cargas fatoriais e as comunalidades de cada fator extraído são apresentadas na Tabela 3.

0 fator 1 conecta motivos que justificam a real ização de negócios internacionais relativos ao mercado doméstico em termos de redução de dependência e riscos e de intensificação da competição. Tais estímulos são derivados das incertezas do mercado doméstico, geralmente relacionadas à disponibilidade de insumos para a produção e às condições dominantes de mercado, dimensões classificadas por Katsikeas e Piercy (1993) e Leonidou (1995) como características ambientais. Esse fator pode ser designado como orientação para o mercado interno. 0 fator 2 , inversamente, une motivos associados ao mercado estrangeiro ou que são fundamentais aos propósitos de internacionalização da firma. Por exemplo, oportunidade de lucro e crescimento no mercado internacional, habilidade para modificar produtos para os clientes internacionais e produção de bens com qualidades únicas ou singulares. Por essa razão, é razoável denominar esse fator competitividade dos produtos para o mercado externo.

0 fator 3 capta o interesse gerencial em relação às atividades internacionais e às crenças gerenciais sobre

Tabela 2 - Caracterização da amostra segundo as variáveis de formação estratégica internacional

\begin{tabular}{|l|c|c|c|c|}
\hline \multicolumn{1}{|c|}{ VARIÁVEIS } & \multicolumn{3}{|c|}{ MEDIDAS DESCRITVAS } \\
\hline & MÉDIA & $P_{25}$ & MEDIANA & $P_{75}$ \\
\hline A idéia da estratégia surgiu da alta administração da empresa. & 4,26 & 4,0 & 5,0 & 5,0 \\
\hline $\begin{array}{l}\text { As decisões sobre o curso da estratégia ficaram sob a responsabilidade da } \\
\text { alta administração. }\end{array}$ & 4,01 & 3,0 & 4,0 & 5,0 \\
\hline $\begin{array}{l}\text { A estratégia foi estabelecida de acordo com os valores, as crenças e os } \\
\text { costumes vigentes na empresa. }\end{array}$ & 3,97 & 3,0 & 4,0 & 5,0 \\
\hline $\begin{array}{l}\text { O desenvolvimento da estratégia foi totalmente controlado pela alta } \\
\text { administração da empresa. }\end{array}$ & 3,96 & 3,0 & 4,0 & 5,0 \\
\hline $\begin{array}{l}\text { A comunicação e a explicitação da estratégia ficaram sob a responsabilidade } \\
\text { da alta administração. }\end{array}$ & 3,82 & 3,0 & 4,0 \\
\hline $\begin{array}{l}\text { A escolha da estratégia ocorreu em um processo seqüencial de análises e } \\
\text { procedimentos. }\end{array}$ & 3,74 & 3,0 & 4,0 \\
\hline $\begin{array}{l}\text { Mesmo depois da implantação da estratégia, continuou-se verificando se ela } \\
\text { estava devidamente ajustada. }\end{array}$ & 3,74 & 3,0 & 5,0 \\
\hline
\end{tabular}


a importância da internacionalização. A literatura tem demonstrado que o capital humano empreendedor é uma das forças-chave para explorar as oportunidades do mercado internacional, e que ele se manifesta pelas percepções, crenças e práticas gerenciais empreendedoras
(Dimitratos e Plakoyiannaki, 2003). Esse fator pode ser nomeado orientação gerencial.

0 fator 4 suscita que o processo de formação de estratégias orientadas para os negócios internacionais ocorre por meio de anál ises rigorosas do ambiente externo, do diálogo

Tabela 3 - Caracterização das cargas fatoriais

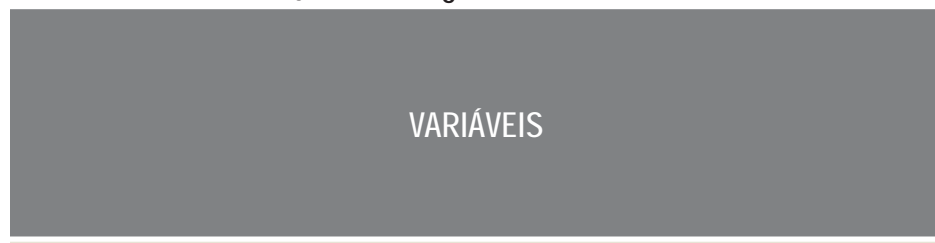

A estratégia se desenvolveu por meio de um diálogo contínuo entre a alta administração e a empresa.

Estabeleceu-se uma agenda de avaliações para acompanhar a implantação da estratégia.

Houve empenho para se chegar a um consenso a respeito da estratégia ser adotada ou não.

Mesmo depois da implantação da estratégia, continuou-se verificando se ela estava devidamente ajustada.

Análises rigorosas do ambiente externo orientaram a decisão de adotar a estratégia.

Habilidades e competências da empresa foram avaliadas no processo de escolha da estratégia.

A implantação da estratégia, uma vez decidida, foi executada em planos formais e detalhados.

0 desenvolvimento da estratégia foi totalmente controlado pela alta administração da empresa.

A idéia da estratégia surgiu da alta administração da empresa.

As decisões sobre o curso da estratégia ficaram sob a responsabilidade da alta administração.

A comunicação e a explicitação da estratégia na empresa ficaram sob a responsabilidade da alta administração.

Necessidade de reduzir a dependência do mercado doméstico.

Intensificação da competição no mercado doméstico.

Necessidade de reduzir os riscos em relação ao mercado doméstico.

Habilidade para modificar produtos para o mercado internacional.

Oportunidade de lucro e crescimento no mercado internacional.

Produção de bens com qualidades únicas ou singulares.

Interesse gerencial em relação a atividades internacionais.

Crenças gerenciais sobre a importância da internacionalização.

Codificacão: Fator 1 = Orientação para o mercado interno.

Fator 2 = Competitividade dos produtos para o mercado externo

Fator 3 = Orientação gerencial.

Fator 4 = Racional-iterativo

Fator $5=$ Top-down

\begin{tabular}{|c|c|c|c|c|}
\hline \multicolumn{3}{|c|}{ FATORES } \\
\hline \\
\hline
\end{tabular}


e do consenso estabel ecido entre a al ta administração e os membros da empresa, do uso de planos formais e detal hados, e da aval iação contínua do processo de implementação. Essas questões sugerem que o processo estratégico internacional das empresas pesquisadas é mais racional e implica uma seqüência de operações que se repetem em termos de avaliações e ajustamentos (Hart, 1992; Smith e Zeithaml, 1999; Crick e Spence, 2004). Esse fator pode ser denominado, então, racional-iterativo.

Por fim, o fator 5 inclui variáveis que indicam a presença marcante da alta administração na concepção, no curso, na comunicação e na explicitação das estratégias internacionais. Esse comportamento mostra que o processo estratégico écentral izado e formulado del iberadamente no nível mais alto da organização, como também articulado em um nível de detal hamento relativamente concreto (M intzberg e Waters, 1985; Hart, 1992; M intzberg, 1998). Esse fator foi denominado top-down.

\section{Características da firma e fatores motivacionais e estratégicos}

Para investigar a existência de diferenças potenciais entre as dimensões motivacional e estratégica estabelecidas pela análise fatorial em relação ao tamanho da firma, à experiência internacional, às estratégias de entrada e ao envolvimento com vendas internacionais, utilizou-se 0 teste $t$ de Student para duas amostras independentes relativas às quatro características da firma mencionadas. Esse teste paramétrico é adequado para pequenas amostras diferentes e permite inferir afirmações sobre médias de populações relacionadas. É importante observar que o teste $F$ foi aplicado e não mostrou diferenças significativas de variância, demonstrando que o pressuposto de igualdade de variâncias não foi violado e que os resultados do teste $t$ foram adequados para comparar as amostras independentes de tamanhos diferentes (Malhotra, 2001).

Os resultados do teste mostram a existência de diferenças significativas em um nível de $p<0,01$ entre as empresas maiores e menores com relação ao fator motivacional orientado para o mercado interno e com relação ao fator estratégico do tipo racional-iterativo. No mesmo nível de significância foram encontradas diferenças entre os modos de entrada em relação ao fator motivacional competitividade dos produtos para o mercado externo e ao fator estratégico racional-iterativo. Em um nível de significância $p<$ 0,05 , constataram-se diferenças quanto ao envolvimento com vendas internacionais em relação ao fator motivacional orientado para o mercado interno e ao fator estratégico do tipo top-down. Não foi observada a existência de diferenças associadas à experiência internacional. Essas evidências são apresentadas na Tabela 4.

Mais especificamente, os resultados da Tabela 4 mostram que as empresas maiores ( média $=0,41$ ) são significativamente mais propensas a realizar negócios internacionais, estimuladas por fatores motivacionais associados ao mercado interno ( $t=-2,84 \mathrm{em} p<0,01)$ quando comparadas com as empresas menores (média $=-0,26$ ). Esses resultados contrariam a premissa de Katsikeas e Piercy (1993) de que as firmas maiores, em comparação com as menores, devem ser mais capazes de perceber e responder a uma variedade mais ampla de sinais associados ao mercado internacional. As empresas da amostra, visivelmente voltadas para os sinais do mercado doméstico, parecem encarar a internacionalização como algo decorrente de pressões internas, e não como uma perspectiva de expansão para além das fronteiras nacionais. A tabela mostrou também que o processo estratégico internacional do tipo racional-iterativo, inspirado na racional idade, no diálogo contínuo entre os principais envolvidos e na realização de ajustamentos contínuos ( $t=-2,83 \mathrm{em} p<$ 0,01 ), é mais significativo nas empresas maiores (média $=0,42$ ) do que nas empresas menores (média $=-0,24$ ). Esses resultados mostram-se convergentes com as evidências anteriores de pesquisa, que pontuaram que o processo estratégico internacional, independentemente do tamanho da firma, combinava estratégias tanto deliberadas quanto emergentes, embora transparecesse que nas grandes empresas era decisiva a presença da al ta gerência conduzindo racionalmente as decisões internacionais (Smith e Zeithaml, 1999).

Em relação à entrada no mercado internacional, os resultados do teste sugerem que as empresas que utilizam estratégias mais avançadas ( média $=0,59$ ) são mais motivadas pelo fator associado à competitividade dos produtos para o mercado externo ( $t=2,80 \mathrm{em} p<0,01$ ) quando comparadas com as empresas que utilizam estratégias mais simples (média =- 0,17). Essas evidências convergem com os dados do relatório da Unctad publicado em dezembro de 2004, que afirma existirem al gumas empresas brasileiras que investem diretamente no estrangeiro, procurando equacionar questões específicas do mercado internacional associadas ao acesso a recursos naturais, ao aperfeiçoamento de infra-estrutura logística ou à necessidade de se aproximar da clientela. Os resultados mostram também que o processo estratégico internacional é mais racional, implican do uma seqüência de operações que se repete em termos de diálogos contínuos, avaliações e ajustamentos $(t=2,84$ em $p<0,01)$, nas empresas que utilizam estratégias mais avançadas de entrada ( édia $=0,60$ ) do que nas 
empresas que utilizam estratégias mais simples (média = - 0,16). Certamente, modos de entrada mais complexos implicam comprometimento maior de recursos, o que justifica que o processo estratégico deva ser formalmente controlado e continuamente discutido com os envolvidos (Smith e Zeithaml, 1999; Lu e Beamish, 2001).

Os resultados da Tabela 4 evidenciam que as empresas mais envolvidas com vendas internacionais (média = - 0,31) são mais motivadas por fatores ligados ao mercado interno ( $t=2,54$ em $p<0,05$ ) quando comparadas com as empresas menos envolvidas ( $m e ́ d i a=0,28$ ), no que se refere, por exemplo, a questões associadas à redução da dependência e dos riscos relativos ao mercado doméstico eà intensificação da competição. Esse resultado contradiz o estudo de Katsikeas e Piercy (1993), que argumenta serem as empresas de maior envolvimento mais direcionadas por condições específicas do mercado internacional ou por dimensões pertencentes a uma política nacional de exportação. Sugere-se que o último aspecto ainda não se apresenta consistente e/ou estável do ponto de vista da estruturação do ambiente econômico-institucional brasileiro em prol do incentivo e do apoio à internacionalização de suas empresas. De outro lado, os dados mostram que a alta administração exerce presença mais marcante nas decisões estratégicas internacionais $(t=-2,00 \mathrm{em} p<$ $0,05)$ das empresas mais envolvidas em termos de volume de vendas no estrangeiro ( $m e ́ d i a=0,25$ ) em comparação com as empresas consideradas menos envolvidas ( média $=-0,20)$. Segundo Smith e Zeithaml (1999), a presença da alta administração émarcante no processo de expansão internacional, tanto comandando o desenvolvimento das estratégias internacionais quanto fornecendo os recursos necessários ao crescimento internacional.

A inexistência de resultados significativos em relação à experiência internacional não permitiu verificar se para as empresas pesquisadas o conhecimento experiencial

Tabela 4 - Comparação dos fatores motivacionais e estratégicos baseados nas características da firma

\begin{tabular}{|c|c|c|c|c|c|}
\hline \multirow[b]{2}{*}{$\begin{array}{c}\text { CARACTERÍSTICAS } \\
\text { DA FIRMA }\end{array}$} & \multicolumn{3}{|c|}{ FATORES MOTIVACIONAIS } & \multicolumn{2}{|c|}{ FATORES ESTRATÉGICOS } \\
\hline & $\begin{array}{c}\text { ORIENTA- } \\
\text { ÇÃO PARA O } \\
\text { MERCADO } \\
\text { INTERNO }\end{array}$ & $\begin{array}{c}\text { ORIENTA- } \\
\text { ÇÃO PARA O } \\
\text { MERCADO } \\
\text { EXTERNO }\end{array}$ & $\begin{array}{l}\text { ORIENTAÇÃO } \\
\text { GERENCIAL }\end{array}$ & $\begin{array}{l}\text { RACIONAL- } \\
\text { ITERATIVO }\end{array}$ & TOP-DOMN \\
\hline Empresas menores & $-0,26$ & $-0,05$ & 0,18 & $-0,24$ & 0,09 \\
\hline Empresas maiores & 0,41 & 0,09 & $-0,20$ & 0,42 & $-0,11$ \\
\hline Valor de $\mathbf{t}$ & $-2,84 * * *$ & $-0,06$ & 1,61 & $-2,83 * * *$ & 0,88 \\
\hline Empresas menos experientes & $-0,24$ & $-0,06$ & 0,16 & $-0,17$ & $-0,16$ \\
\hline Empresas mais experientes & 0,07 & 0,02 & $-0,01$ & 0,08 & 0,07 \\
\hline Valor de $\mathbf{t}$ & $-1,12$ & $-0,31$ & 0,65 & $-0,85$ & $-0,86$ \\
\hline Modos simples de entrada & $-0,11$ & $-0,17$ & 0,18 & $-0,16$ & 0,13 \\
\hline Modos avançados de entrada & 0,37 & 0,59 & 0,64 & 0,60 & $-0,02$ \\
\hline Valor de $\mathbf{t}$ & $1,71^{*}$ & $2,80 * * *$ & 0,16 & $2,84 * * *$ & 0,61 \\
\hline Empresas menos envolvidas & 0,28 & $-0,19$ & $-0,11$ & $-0,03$ & $-0,20$ \\
\hline Empresas mais envolvidas & $-0,31$ & 0,22 & 0,19 & 0,08 & 0,25 \\
\hline Valor de $\mathbf{t}$ & $2,54 * *$ & $-1,79 *$ & $-1,35$ & $-0,50$ & $-2,00 * *$ \\
\hline
\end{tabular}

Codificação: Empresas menores $=500$ empregados ou menos $(n=43)$

Empresas maiores $=501$ empregados ou mais $(n=30)$

Empresas menos experientes $=10$ anos ou menos de atuação no exterior $(n=18)$

Empresas mais experientes $=11$ anos ou mais de atuação no exterior $(n=55)$

Estratégias mais simples de entrada $=$ exportação e contratos de produção $(n=56)$

Estratégias mais avançadas de entrada = parcerias, aquisição e investimentos greenfield $(n=17)$

Empresas menos envolvidas $=55,0 \%$ ou menos de vendas internacionais $(n=38)$

Empresas mais envolvidas $=56,0 \%$ ou mais de vendas internacionais $(n=35)$

*** Significância $p<.01$

** Significância $p<.05$.

* Significância $p<.10$. 
pode gerar oportunidades de negócios e impulsionar decisões mais claras e amplas de comprometimento de recursos com o mercado internacional, conforme sugerido pela literatura (veja Johanson eW iedersheim-Paul, 1975; Johanson e Vahlne, 1977, Gripsrud, 1990; Katsikeas e Piercy, 1993). Seria necessário realizar uma investigação em profundidade com as empresas envolvidas no estudo para levantar possíveis razões para esses resultados.

\section{CONCLUSÃO}

Este artigo apresentou três contribuições importantes. A primeira é que foi possível identificar que as empresas brasileiras de manufatura pesquisadas, apesar de demonstrarem experiência internacional e envolvimento com vendas internacionais, utilizam estratégias de entrada consideradas de menor complexidade ecomprometimento de recursos. Isso sugere um baixo grau de internacional ização, uma vez constatada a não opção por investimentos diretos no estrangeiro.

Em relação à segunda contribuição, uma estrutura de cinco fatores foi revelada com base em evidências empíricas anteriores. Três desses fatores indicaram que os motivos que impulsionam a realização de negócios internacionais se associam a elementos ligados aos mercados interno e externo, e a elementos de ordem gerencial. Todavia, ficou também evidenciado que as empresas pesquisadas, de um lado, não se beneficiam de subsídios públicos ou institucionais para as suas operações internacionais e que, de outro lado, talvez precisem se tornar mais empreendedoras como forma de obter vantagem das oportunidades que surgem no mercado internacional. Outros dois fatores determinaram que 0 processo de formação estratégica é significativamente contornado por estratégias central izadas na al ta administração e desenvolvidas por meio da racionalidade.

Q uanto à terceira contribuição, demonstrou-se a existência de diferenças potenciais significativas entre a estrutura de fatores motivacionais e estratégicos revelada e o tamanho da firma, os modos de entrada utilizados e 0 envolvimento com vendas internacionais. 0 mesmo não ocorre com a experiência internacional. Empresas maiores se estimulam internacional mente por motivos específicos do mercado doméstico e desenvolvem um processo estratégico internacional inspirado na racional idade e em uma seqüência de operações que se repetem em termos de avaliações e ajustamentos contínuos. Empresas que utilizam modos mais avançados também são envolvidas por decisões baseadas na racionalidade, porém se motivam por fatores particulares do mercado internacional.
Inversamente, fatores ligados ao mercado doméstico impulsionam as empresas mais envolvidas com vendas internacionais, com a presença marcante da al ta administração no comando do processo estratégico internacional.

Finalmente, é oportuno ressaltar algumas limitações do estudo. Primeira, a análise ex post facto, apesar de ser largamente utilizada em pesquisas sobre negócios internacionais, pode apresentar vieses difíceis de equacionar, por exemplo, aqueles que poderiam resultar da investigação dos motivos subjacentes às decisões internacionais de uma firma que atua há muitos anos no mercado estrangeiro (Katsikeas e Piercy, 1993). Quanto à segunda limitação, o tamanho da amostra final - apesar de atender às exigências de aplicação das técnicas estatísticas utilizadas -, não proporciona bases suficientes para se fazerem generalizações. Em relação à terceira limitação, instrumentos de pesquisa que utilizam fontes primárias de levantamento de dados são susceptíveis a julgamentos pessoais, que podem introduzir erros significativos na medição dos resultados, não obstante 0 instrumento de coleta dos dados ter sido pré-testado com acadêmicos e executivos diretamente envolvidos com negócios internacionais. Além disso, a abordagem quantitativa não exaure as complexidades envolvidas em estudos sobre negócios internacionais, devendo-se utilizar abordagens qualitativas para fins de aprofundamento dos dados.

\section{REFERÊNCIAS}

ANDERSEN , O. Internationalization and market entry mode: a review of theories and conceptual frameworks. M anagement International Review, $v$. 37 , n. 2, p. 27-42, 1997

BUCKLEY, P. J.; CASSON, M. C. Analysing foreign market entry strategies: extending the internalization approach. Journal of International Business Studies, v. 29, n. 3, p. 539-562, 1998.

CRICK, D.; SPENCE, M. The internationalisation of 'high performing' UK high-tech SME's: a study of planned and unplanned strategies. International Business Review, v. 20, p. 1-19, 2004.

DIAMANTOPOULOS, A.; INGLIS, K. Identifying differences between high and low-involvement exporters. International Marketing Review, v. 5, n. 2, p. 52-60, 1988.

DIMITRATOS, P.; PLAKOYIANNAKI, E. Theoretical foundations of an international entrepreneurial culture. Journal of International Entrepreneurship, v. 1, n. 2, p. 187-215, 2003.

GRIPSRUD, G. The determinants of export decisions and attitudes to a distant market: N orwegian fishery exports to Japan. Journal of International Business Studies, v. 21, n. 3, p. 469-485, 1990. 
HAIR JR, J. F.; ANDERSON, R. E.; TATHAM, R. L.; BLACK, W. C. Multivariate Data Analysis. New Jersey: Prentice Hall, 1998.

HART, S. L. An integrative framework for strategy-making process. Academy of M anagement Review, v. 17, n. 2, p. 327-351, 1992.

HILL, C. W. L.; HWANG, P.; KIM, W. C. An eclectic theory of the choice of international entry mode. Strategic Management Journal, v. 11, n. 2, p. 117-128, 1990.

HOLZMULLER, H. H.; KASPER, H. Personal and organizational determinants of export trade activities observed in small and medium-sized firms. M anagement International Review, v. 31, Special Issue, p. 45-70, 1991.

JOHANSON, J.; VAHLNE, J. E. The internationalization process of the firm: a model of knowledge development and increasing foreign market commitments. Journal of International Business Studies, v. 8, n. 1, p. 23-32, 1977.

JOHANSON, J.; WIEDERSHEIM-PAUL, F. The internationalization of the firm: four Swedish cases. The Journal of Management Studies, v. 12, n. 3, p. 305-322, 1975.

KATSIKEAS, C. S. Ongoing export stimulation: differences between regular and sporadic exporters. International Marketing Review, v. 13, n. 2, p. 4-19, 1996.

KATSIKEAS, S. C.; PIERCY, N. F. Long-term export stimuli and firm characteristics in a European LDC. Journal of International Marketing, v. $1, n$. 3, p. 23-47, 1993.

LEONIDOU, C. L. Export stimulation research: review, evaluation and integration. International Business Review, v. 4, n. 2, p. 133-156, 1995.

MALHOTRA, N. K. Pesquisa de marketing. Porto Alegre: Bookman, 2001.

LU, J. W.; BEAMISH, P. W. The internationalization and performance of SMEs. Strategic M anagement Journal, v. 22, n. 6-7, p. 565-586, 2001.

MELIN, L. Internationalisation as a strategy process. Strategic M anagement Journal, v. 13, Special Issue, p. 99-118, Winter, 1992.
MERILEES, B.; MILLER, D.; TIESSEN, J. Serendipity, leverage and the process entrepreneurial internationalization. Small Enterprise Research, $\mathrm{v}$. 6, n. 2, p. 3-11, 1998.

MINTZBERG, H. A criação artesanal da estratégia. In: MONTGO MERY, C. A.; PORTER, M. E (Orgs.). Estratégia: a busca da vantagem competitiva. Rio de Janeiro: Campos, 1998.

MINTZBERG, H.; WATERS, J. A. Of strategies, deliberate and emergent. Strategic Management Journal, v. 6, n. 3, p. 257-272, 1985.

ORGANIZAÇÃO DASNAÇÕESUNIDAS. Unctad O casional N ote. Outward FDI from Brazil: poised take off? N ova York e Genebra, dez. 2004.

RO OT, F. R. Entry strategies for international markets. New York: Lexington Books, 1994.

SHANE, S.; VENKATARAMAN, S. The promise of entrepreneurship as a field of research. Academy of Management Review, v. 25, n. 1, p. 217$226,2000$.

SMITH, A. D.; ZEITHAML, C. The intervening hand: contemporary international expansion of the regional bell operating companies. Journal of M anagement Inquiry, v. 8, n. 1, p. 34-64, mar. 1999.

SPENCE, M. International strategy formation in small Canadian hightechnology companies: a case study approach. Journal of International Entrepreneurship, v. 1, p. 277-296, 2003.

ZAHRA, S. A; IRELAND, D. R.; HITT, M. A. International expansion by new venture firms: international diversity, mode of markety entry, technological learning and performance. Academy of Management Journal, $\mathrm{v}$. 43, n. 5, p. 925-950, 2000.

ZAHRA, S. A.; CORRÍ, J. S.; YU, J. Cognition and entrepreneurship: implications for research on international opportunity recognition and exploitation. International Business Review, v. 20, p. 1-18, 2004.

\section{Artigo recebido em 22.11.2005. A provado em 11.06.2006.}

\section{Luiz Honório}

Doutor pelo Centro de Pesquisas e Pós-Graduação em Administração Cepead-FACE-UFMG. Professor titular do mestrado acadêmico da Faculdade Novos Horizontes.

Interesses de pesquisa nas áreas de gestão internacional, administração estratégica e novas tecno-

logias gerenciais.

E-mail: luizhonorio@unihorizontes.br

Endereço: Rua Ramalhete, 115/204, Bairro Anchieta, Belo Horizonte - M G, 30310-310.

\section{Suzana Braga Rodrigues}

Professora da Faculdade de Administração, Contabilidade e Economia da Universidade Fundação Mineira de Educação e Cultura (FACE-Universidade FUMEC). Coordenadora do Mestrado em N egócios Internacionais da Birmingham University, Inglaterra. PhD pela University of Bradford. Interesses de pesquisa nas áreas de cultura, governança corporativa e gestão internacional.

E-mail: sbrodrigues@task.com.br

Endereço: Rua Engenheiro Sena Freire, 578, Bairro São Bento, Belo Horizonte - MG, 30350-400. 